\title{
Modeling Asymmetric Effects and Long Memory in Conditional Volatility of Dhaka Stock Exchange: New Evidence from Family of FIGARCH Models
}

\author{
Muhammad Enamul Haque*, Nusrat Farzana \\ School of Business \& Economics, United International University, Madani Avenue, Dhaka, Bangladesh
}

Received June 2, 2021; Revised July 10, 2021; Accepted August 22, 2021

\section{Cite This Paper in the following Citation Styles}

(a): [1] Muhammad Enamul Haque, Nusrat Farzana , "Modeling Asymmetric Effects and Long Memory in Conditional Volatility of Dhaka Stock Exchange: New Evidence from Family of FIGARCH Models," Universal Journal of Accounting and Finance, Vol. 9, No. 5, pp. 1103 - 1115, 2021. DOI: 10.13189/ujaf.2021.090520.

(b): Muhammad Enamul Haque, Nusrat Farzana (2021). Modeling Asymmetric Effects and Long Memory in Conditional Volatility of Dhaka Stock Exchange: New Evidence from Family of FIGARCH Models. Universal Journal of Accounting and Finance, 9(5), 1103 - 1115. DOI: 10.13189/ujaf.2021.090520.

Copyright $\odot 2021$ by authors, all rights reserved. Authors agree that this article remains permanently open access under the terms of the Creative Commons Attribution License 4.0 International License

\begin{abstract}
This paper investigates modeling the conditional volatility of the Bangladesh equity market, namely the Dhaka Stock Exchange benchmark index (DSEX) and the Shariah Index (DSES), to explore the presence of leverage effects and long memory behavior covering the period from July 01, 2004 to December 31, 2020. We employ a family of Fractionally Integrated GARCH models FIFARCH BBM, FIGARCH CHUNG, FIEGARCH, FIAPARCH BBM, FIAPARCH CHUNG, and HYGARCH to capture both asymmetric effects and long memory behavior in conditional variance, a unique study in volatility literature. We detect strong evidence in favor of asymmetric effects and long memory behavior in the conditional volatility of DSEX and DSES returns, which repudiates the weak-form efficient market hypothesis. The study reveals FIEGARCH and FIAPRACH CHUNG outperform the other fractionally integrated GARCH specifications in modeling conditional volatility of equity returns. The paper further examines the diagnostic test of misspecification of the conditional variance equation based on the news impact curve, and results ensure that all models are fairly specified. This study also looks into the risk-return tradeoff in time-varying volatility and finds no evidence of the positive relationship between equity returns and volatility dynamics. The findings have pragmatic implications for retail and wholesale investors and other market players to initiate the investments and hedging strategies before
\end{abstract}

investing in an emerging equity market like Bangladesh.

Keywords Asymmetric Effects, Long Memory, Family of Fractionally Integrated GARCH Models, Dhaka Stock Exchange

JEL Classification: C22, G10, G15

\section{Introduction}

The equity market is presupposed as a vehicle of investments involving inherent uncertainty in every economy. Switching from investment in risk-free bank accounts to risky equity markets constraints a tradeoff between risk and returns for risk-averse investors. The connotation of volatility is symbolized as a measurement of risk. Higher volatility designates a considerable variation of equity returns and hence a greater risk. Cognizance of volatility is momentous for portfolio investment decisions, risk management decisions for various funds managers, hedging and speculation strategies applied by institutional investors, and other asset pricing decisions. Researchers and other equity market players adopt different measures to model the conditional variance of equity returns to explore some common properties of return volatility observed from 
empirical studies. Stylized facts are another name for these properties. Volatility clustering, seasonality effect, leverage effect, asymmetric effect, long memory, risk-return tradeoff, and other stylized facts are well-known to be exemplified by asset prices [1], [2] Three well-documented properties of return volatility are to be investigated in the current study: risk-return tradeoff, leverage or asymmetric effects, and long memory in volatility. The observed properties in returns volatility are more articulated in emerging markets than developed equity markets, as supported by empirical studies [3] - [8].

One of the elementary assumptions of traditional econometric models assumes that variance should remain constant at a different time interval. Financial time series, particularly stock returns, unveil some important characteristics, including fat-tailed distributions volatility persistence and volatility clustering, asymmetric volatility shocks, and long memory behavior in conditional volatility.

To model these real-world returns volatility phenomena, we require a non-constant or heteroscedasticity-based model. This is why GARCH-type models have become very popular and prove consistent in describing how corrections for heteroscedastic error disturbances can lead to more efficient estimates of the parameters for the return's series. Most of the empirical studies applied a variant of GARCH-type specifications to model the conditional volatility of the stock returns. The standard GARCH [9], the asymmetric EGARCH [10] and the GJR-GARCH [11], integrated GARCH [12], fractionally integrated GARCH [13],fractionally integrated exponential GARCH [14], the asymmetric power GARCH [15], are widely used in volatility literature [16][20];[7];[21];[22];[8]. In modeling the asymmetric effects and long memory property in conditional volatility of the Bangladesh equity market, no empirical study is conducted adopting the family of Fractionally Integrated GARCH models. Therefore, it would be a riveting effort in this study to apply the variants of GARCH-type specifications to model the conditional volatility of the Bangladesh stock market.

The characteristics of emerging markets are much more congenial to document the stylized facts of return volatility and have paramount implications in determining the efficiency of the equity markets. We use the Dhaka Stock Exchange benchmark index (DSEX) and Shariah Index (DSES) in the study to investigate these volatility characteristics in the context of the surprising and outlandish behavior of emerging equity markets like Bangladesh.

The study can grab the attention of the following motivations. This is the first study of its kind for the Bangladesh equity market that accommodates these three volatility phenomena in a single study and a large sample size. The second aspect of this paper enriches the existing volatility literature by scrutinizing the volatility performance of the Shariah index with the performance of the conventional benchmark market index. Lastly, this study examines the evidence of long memory behavior in volatility applying a family of fractionally integrated GARCH models (FIGARCH BBM and CHUNG, FIEGARCH and CHUNG, FIAPARCH BBM and CHUNG, and HYGARCH), which is scarcely ever-present in modeling the return volatility.

\section{Literature Review}

Volatility measures how far a stock's or the market's overall portfolio has deviated from expected returns. On the other hand, volatility has risks associated with a specific stock market or the entire stock market [8]. Volatility is not only a measure of overall financial risk, but it also causes concern among investors and regulators [23]. Over the year, many scholars work with volatility properties, and enormous literature covers the study of volatility. Three well-documented properties of volatility are the leverage effect, the risk-return tradeoff, and long memory.

\subsection{Risk- Return Tradeoff}

The risk-return tradeoff describes any risk premium in the equity market or the relationship between expected return and risk. Any increase in conditional variance should be compensated with the corresponding rise in the market's average returns. All the finance theories like CAPM, APT, Portfolio theory presume a constructive association between risk and return in the equity market supported by various empirical studies [24] - [27]. This property implies that it enables market participants to estimate returns' elasticity concerning the volatility changes. The risk-return relationship is one of the most discussed subjects in finance, but it is also one of the most divisive. Mollah \& Mobarek [28] look at the time-varying risk-return relationship and the persistence of volatility shocks in developed and emerging markets using the GARCH method. Al Refai et al. [29] aim to look at asymmetric volatility and the risk-return Tradeoff in Jordan's emerging stock market at the sector level and find some proof of a positive relationship between risk and return before the crisis period. There is a negative but negligible risk-return relationship during the crisis, and negative shocks have a greater effect than positive ones. Albaity \& Ahmad [30] examine the returns and volatility of three Islamic stock market indices, namely the DJIMI, the FTSEGII, and the KLSI listed in the United States, the United Kingdom, and Malaysia. They find risk premium is absent for each index with no noticeable difference in returns. Kuttu [31] studies the returns and volatility dynamics of thin-traded modified equity returns from Ghana, Kenya, Nigeria, and South Africa using a 
multivariate VAR-EGARCH model and finds the persistent presence of volatility.

\subsection{Asymmetric Effects}

In an economic sense, any drop in the stock price (which signifies the negative return) will lead to decline in the firm's value. This aspect forces the firm to become more leveraged as the given value of debt increases relative to equity value. As a result, it is imperative to believe that the firm's equity possesses a greater risk and becomes more volatile. This phenomenon can be regarded as the leverage effects, also known as the asymmetric effects, as per empirical volatility findings. The interpretation of the leverage effect is that equity returns should be negatively correlated with the changes in volatility and originated from the studies of [32] and [33]. The natural tendency of volatility became more sensitive with respect to any negative (bad news) shocks about the stock than the kind of positive shocks (positive news), and it triggered as investment signals to market participants.

The "leverage effect" is a recognized relationship between stock returns and implied and realized volatility: volatility rises when the stock price falls [33]. A review of the various studies on stock market volatility and leverage effect reveals that many financial analysts and academics have addressed this topic. But the majority of them have focused on the developed countries' scenario. Despite being one of the most misunderstood concepts in investing, the relationship between firm-specific variables and volatility movement, especially the leverage effect, endures fascinating finance researchers, investors, market analysts, regulators, and the general public. Portfolio management, predominantly asset allocation, asset pricing, portfolio selection, portfolio diversification, and risk management, are all influenced by the volatility and leverage effect configurations in financial markets [1]; [23]; [34]. When bad news about a company's value hits the financial markets, the company's value plummets, resulting in a high debt-to-equity ratio. The firm's equity risk rises due to this financial leverage channel, reflected in high volatility [35]. Using the daily All Shares Index of the Nigerian Stock Exchange Herbert et al.[23] investigated the Nigerian stock market, the phenomenon of volatility clustering, and leverage effect (asymmetry) in stock returns. The results show volatility clustering, persistent clustering, and significant leverage impact on stock returns in the Nigerian stock market. The use of generalized autoregressive conditional heteroskedasticity (GARCH)-class models to forecast asset price volatility is supported by a wide body of literature on volatility modeling. Such as; [36] - [40]. GARCH \& GRJ-GARCH model is used to measure the effect of leverage on stock market volatility also. According to the GARCH model, current stock market volatility can be explained by past volatility that tends to persist over time. Maiti \& Bidinger
[41] applies GARCH \& EGARCH model and reveals that the leverage effect is greater in the case of the UK stock market.

\subsection{Long Memory in Volatility}

The third volatility phenomenon that can be very efficacious for the equity market participants is the long-range dependence known as long memory in volatility [13]. The meaning of long memory can be interpreted as the persistence of shocks remain long-lasting and decline slowly at a hyperbolic rate, but their impact would continue to decline much faster exponentially. Its presence represents the nonlinear dependence in the first moment of the return distributions and provides a potentially predictable structure. There should be an opportunity for the investors to consistently make speculative (abnormal) profits if long memory prevails in equity markets, which will contradict the martingale or random walk process of return series that any financial asset pricing theory assumes. Its presence in the equity market challenges the weak form efficiency hypothesis that specifies that the past value of market returns cannot influence the predicting behavior of future returns.

Considerable evidence has been found based on the analysis of long memory and volatility of stock returns [42] - [45]. Bentes et al. [37] looked at long memory and volatility clustering for the S \& P500, NASDAQ100, and Stoxx 50 indexes to compare the US and European markets and realize that they might better understand the degree of volatility clustering and long-memory effects by evaluating the entropy values for various evenly spaced sub-periods, which is something that will be explored further. Choudhry [38] investigates the fractional integration (long memory) of time-varying beta from Hong Kong, Malaysia, and Singapore markets \& results show that all three-time varying betas are long memory or slow mean-reverting. Floros et al.[39] used (ARFIMA), (GARCH), and ARFIMA-FIGARCH models to search for the existence of fractional integration, or long memory, in the regular returns of the Portuguese stock market. The findings of the entire sample demonstrate that long memory has a strong impact on stock returns. Mokni \& Mansouri [46] examine the relationship between the major international stock markets when considering the long memory in volatility during structural changes. Duppati et al.[47] determined the degree to which intraday data of five Asian equity indices are used to describe and predict long-term memory. Abdul Manap \& Kassim [48] focused on the Malaysian share market to investigate the long memory property of equity returns and volatility of emerging equity markets. Vougas [41] finds weaker evidence in favor of long memory's impact on volatility by taking the data of Athens stock exchanges.

The study of stock market volatility and the 
explanations for it that go beyond price fluctuations have always been important in financial theory. It has sparked a heated debate in which long memory and volatility clustering have proved to be especially important. The existence of a long-memory variable in volatility has been documented in the recent empirical literature. Despite a favorable risk-return tradeoff and long memory in volatility, Beran \& Schützner [2] shows that volatility shocks have a trivial and short-term effect on stock prices.

Walther [36] analyzed long memory and asymmetry effects considering the two types of indices of the Vietnamese stock market. The result discloses disparities in the asymmetric effects of negative and positive news on volatility and shock perseverance (long memory). Crato \& de Lima [49] re-examine the presence of long-memory and nonlinear dynamics in some popular stock market indexes using new time series analysis to understand the financial market activities. Result reveals no proof of long-memory on the sequence of returns while searching for the presence of long-memory. However, in the sequence of squared returns, strong evidence for persistent long-run dependency is discovered. There are no studies investigated on DSEX and DSES indices of the Bangladesh equity market applying these variant of GARCH-type specification modeling the conditional volatility.

\section{Methodology}

We examine in the study the two equity indices in Bangladesh, which are the DSEX and DSES. DSEX is the broad market index of the Dhaka Stock Exchange, also known as the benchmark index. The DSES is a Shariah index that provides broad market coverage of Shariah-compliant equities listed on the Dhaka Stock Exchange. The data for both indices are generated from Thomson Reuter Eikon. The data span for DSEX covers July 1, 2004-December 31, 2020, with total observations of 3943 and DSES from January 20, 2014, to December 30, 2020, with a total observation of 1647.

Dhaka Stock Exchange benchmark index remains, on average, stable from 2000 to early 2004 . There was very low volatility clustering observed during these periods. In addition, we did not find any ARCH effects for the data series, which is a necessary condition for applying any GARCH-type specification for modeling the conditional volatility. Therefore, the study used the DSEX index data sample starting from July 01, 2004.

Stock market returns are calculated as continuously compounded returns known as natural log-returns and is expressed as:

$$
r_{t}=\operatorname{LN}\left(\frac{P_{t}}{P_{t-1}}\right) * 100
$$

Pt and Pt-1 are the closing prices of the market index at days $t$ and $t-1$.

\section{GARCH-M Model}

The returns of equity are conditional on its volatility (conditional variance. According to finance theory, risk-averse investors necessitate the premium as compensation to accept a risky investment. The GARCH-M model captures this phenomenon. It allowed a time-varying risk premium to account for whether the risks and expected returns are correlated. That is,

$$
Y_{t}=\omega+\xi h_{t}+\mu_{t}
$$

The conditional variance is defined by:

$$
\begin{gathered}
h_{t}=\phi+\sum_{k=1}^{p} \theta_{k} h_{t-k}+\sum_{i=1}^{q} b_{i} \mu_{t-i}^{2} \\
\phi_{>0,} \theta \geq 0, \mathrm{~b} \geq 0
\end{gathered}
$$

\subsection{Asymmetric Conditional Volatility Models}

\section{EGARCH Model}

The exponential GARCH (EGARCH) model developed by [50] withdraws the typical nonnegative constraints on the model parameters and accommodates asymmetric features (with the assumption that negative (positive) shocks could have a larger effect on conditional volatility than positive (negative) shocks. EGARCH model can be specified as:

$$
\log \left(h_{t}\right)=\phi+\sum_{i=1}^{q} \eta_{i}\left|\frac{\mu_{t-1}}{\sqrt{h_{t-1}}}\right|+\sum_{i=1}^{q} \lambda_{i} \frac{\mu_{t-1}}{\sqrt{h_{t-1}}}+\sum_{k=1}^{p} \theta \log \left(h_{t-k}\right)
$$

The $\log \left(h_{t}\right)$ makes the model exponential rather than quadratic and satisfies the condition of nonnegative estimates. $\eta_{i}$ represents the size effect of innovation, and $\lambda_{i}<0$ illustrates the asymmetric feature of the model.

\section{GARCH GJR Model}

Threshold GARCH (TGARCH) introduced by [51] and [11] is another GARCH variant model that encompasses asymmetric features with respect to positive and negative innovations. This model entertains the multivariate dummy variable into the variance equation to test whether negative shocks are statistically significant. The variance equation for T-GARCH for higher-order is given by

$$
h_{t}=\phi+\sum_{k=1}^{p} \theta_{1} h_{t-k}+\sum_{i=1}^{q}\left(b_{i}+\gamma_{i} D_{t-i}\right) \mu_{t-i}^{2}
$$

D takes the value of 1 when $\mu_{t}<0$ and 0 otherwise. Positive shocks (good news) are represented by $b_{1}$, while negative shocks show the impact of $b_{1}+\gamma_{1}$. Positive $\gamma_{i}$ 
indicates the presence of asymmetry.

\subsection{Long Memory Conditional Volatility Models}

The concept of long memory into conditional volatility can be absorbed by observing empirical autocorrelations of the squares of financial time series decay very slowly in general. A time-series process $(\mathrm{Xt})$ is said to have long memory if it is second-order stationary and satisfies, for $\mathrm{h}$

$$
\begin{gathered}
\left|\operatorname{Cov}\left(X_{t}, X_{t-h}\right)\right| \sim K h^{2 d-1} \\
h \rightarrow \infty,
\end{gathered}
$$

Where, $\mathrm{d}<1 / 2$ and $\mathrm{K}$ is a nonzero constant.

It represents a long memory process for which and thus

$$
\sum_{h=-\infty}^{+\infty} \mid \operatorname{Cov}\left(X_{t}, X_{t-h} \mid=\infty\right.
$$

\section{FIGARCH Model}

The fractionally integrated autoregressive conditional heteroscedasticity (FIGARCH) model of [9] captures persistence in conditional volatility and becomes comfortable in describing the behavior of observed dependencies in equity market volatility. The conditional variance under the FIGARCH model can be developed as:

$$
\begin{gathered}
\sigma_{t}^{2}=\omega\left[1-\beta(L)^{-1}+\left\{1-\left(1-\beta(L)^{-1} \phi(L)(1-L)^{d}\right\} \mu_{t}^{2}(7)\right.\right. \\
\sigma_{t}^{2}=\omega\left[1-\beta(L)^{-1}+\lambda(L) \mu_{t}^{2}\right.
\end{gathered}
$$

$\mathrm{d}$ refers to the fractional difference parameter that measures the degree of long memory behavior. L represents the lag operator, $\mathcal{E}_{t}^{2}$ justifies the white noise residual process, $(1-L)^{d}$ is the fractional differencing operator.

Chung (1999) readdresses a FIGARCH model, pointing out that the model of [9] may have structural problems that can lead to the biased interpretation of parameter estimation. The fractional differencing operator has applied in constant terms to the mean equation but not in the variance equation. Therefore, Chung proposed the following alternative FIGARCH model:

$$
\delta(L)(1-L)^{d}\left(\varepsilon_{t}^{2}-\sigma^{2}\right)=[1-\beta(L)]\left(\varepsilon_{t}^{2}-\sigma_{t}^{2}\right)
$$

Where, $\sigma^{2}$ is the unconditional variance of $\varepsilon_{t}$. D is the long memory parameter. Alternatively, the conditional variance can be expressed as:

$$
h_{t}=\sigma^{2}+\left[1-\{1-\beta(L)\}^{-1} \delta(L)(1-L)^{d}\right]\left(\varepsilon_{t}^{2}-\sigma^{2}\right)
$$

Under the framework of the fractionally integrated model, [14] transforms the FIGARCH process into a fractionally integrated exponential GARCH (FIEGARCH) that corresponds to [50] exponential GARCH model to capture the aspect of asymmetry. Model is described as:

$$
\operatorname{In}\left(h_{t}\right)=\omega+\delta(L)^{-}(1-L)^{-d}[1+\alpha(L)] g\left(z_{t-1}\right)
$$

Where, $\delta(L)$ and $\alpha(L)$ are the non-stochastic scaler sequences of backshift operator $\mathrm{L}$ of different orders. The value $g\left(z_{t-1}\right)$ should be the function of magnitude and the of sign of $z_{t}$.

[15] proposed a fractionally integrated conditional volatility model, which combines the feature of a fractionally integrated model of [9] and asymmetric power ARCH of Ding et al. (1993). The model becomes FIAPARCH GARCH and is specification as:

$$
\sigma_{t}^{\sigma}=\omega+\left[1-\{1-\beta(L)\}^{-1} \delta(L)(1-L)^{d}\right]\left(\left|\varepsilon_{t}\right|-\gamma \varepsilon_{t}\right)^{\theta}
$$

Where, $d$ indicates the fractional difference parameter, $\gamma$ defines the asymmetric component of the model, and negative value signifies that negative shocks will have more effects on volatility than the positive shocks. The FIAPARCH process can also be reduced to the FIGARCH model if $\gamma=0$ and $\delta=2$.

[52] formulates an improvement Hyperbolic GARCH model known as HYGARCH over the FIGARCH process criticizing its property that it has infinite variance and can be defined:

$$
\begin{gathered}
y_{t}=\varepsilon_{t} \sqrt{h_{t}} \\
h_{t}=\frac{\gamma}{\beta(1)}+\left\{1-\frac{\omega_{H}(B)}{\beta(B)}\left[1-\delta+\delta(1-B)^{d}\right]\right\} h_{t}^{2}
\end{gathered}
$$

\section{Results and Discussion}

The study begins with the summary of descriptive statistics to understand the nature of DSEX broad index and DSES Shariah index distributions and make sure that the necessary conditions are satisfied with the data series to apply the GARCH type models. Table 1 outlines the results of descriptive statistics.

Table 1. Descriptive Statistics

\begin{tabular}{ccc}
\hline & DSEX Index & DSES Index \\
\hline Mean & 4121 & 1164 \\
Median & 4480 & 1147 \\
Minimum & 1185 & 834 \\
Maximum & 8918 & 1433 \\
Standard Deviation & 1599 & 119 \\
CV & 0.39 & 0.10 \\
Skewness & -0.16 & 0.06 \\
Excess Kurtosis & -0.65 & -0.75 \\
Jarque-Bera Test & 87.44 & 40.26 \\
& {$[0.00]$} & {$[0.00]$} \\
Shapiro Wilk W Test & 0.95 & 0.98 \\
Unit Root and ARCH Effect Test & \\
\hline \multirow{2}{*}{ ARP } & {$[.000]$} & -11.04 \\
ADF Test Statistics & {$[0.00]$} & {$[0.00]$} \\
& 0.3007 & 0.120 \\
KPS Test Statistics & {$[0.00]$} & {$[0.00]$} \\
ARCH LM Test & 181.25 & 116.40 \\
Statistics & {$[0.00]$} & {$[0.00]$} \\
\hline
\end{tabular}

Note: $\mathrm{P}$-value is given in parentheses

The value of skewness shows that the DSEX series has 
a long-left tail and DSES has a long right tail. Kurtosis value indicates that both price indices represent the platykurtic distributions. The null hypothesis of normality has been rejected by the Jarque-Bera and Shapiro Wilk test statistics supported by p-values that confirm that DSEX and DSES series are not normally distributed. Table 1 also reports the results of unit root tests from Augmented Dickey- Fuller (ADF) and KwiatkowskiPhillips-Schmidt-Shin (KPSS) and substantiates that both indices' return series are stationary. Before we apply any GARCH type model, it obliges that data series must be stationary and have an ARCH effect. LM statistics' value pinpoints that the null hypothesis of no ARCH effect is rejected for both the indices returns series, which is confirmed by statistically significant $p$ values and affirms that data possesses ARCH effect. The results confirm the tests of sufficient conditions to apply any GARCH type model in the current study.

Figure 1 and 2 feature the Dhaka Stock Exchange benchmark index(DSEX) and Shariah Index(DSES) return series. Both the indices series explicitly confirm the presence of volatility clustering over the sample period, a necessary condition for modeling the GARCH type specification for time series data.

DSES Return Series

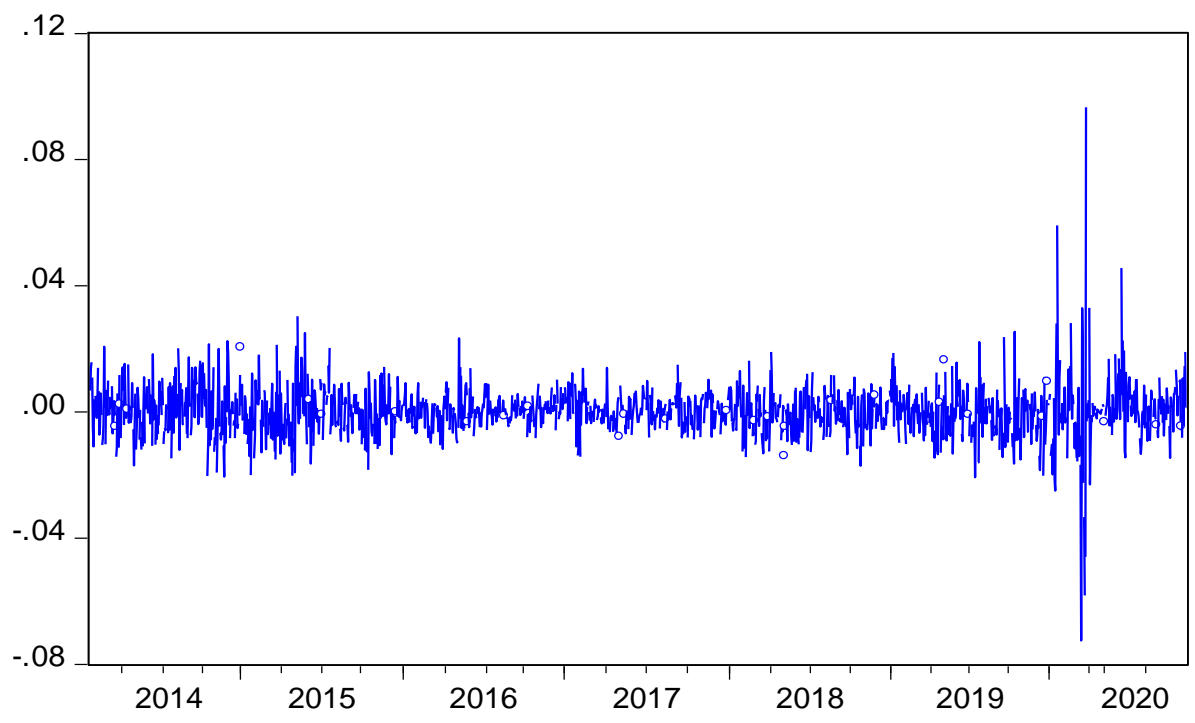

Figure 1. Dhaka Stock Exchange Benchmark Index(DSEX)

DSEX Return Series

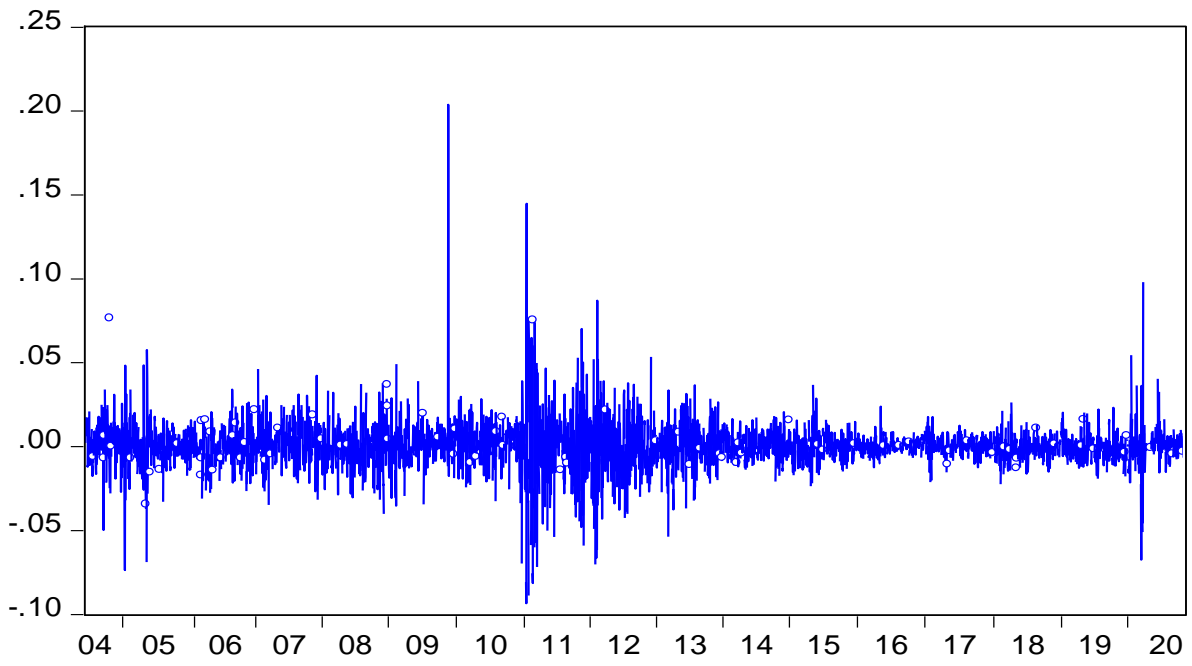

Figure 2. Dhaka Stock Exchange Shariah Index (DSES) 


\subsection{Test of Asymmetric Conditional Volatility}

The study examines two univariates conditional GARCH models to test asymmetric shocks on conditional volatility: the exponential general autoregressive conditional heteroscedasticity (EGARCH) and the threshold general autoregressive conditional heteroskedasticity (TGARCH). Table 2 reports the results of the EGARCH model for both DSEX and DSES indices of the Dhaka stock exchange. The negative and statistically significant lambda coefficients signify the presence of leverage effect in the Bangladesh equity market. The results suggest that the lambda parameters are negative and statistically significant for the conventional and the Shariah indices under both error distribution methods. There is a negative association between past returns and the future volatility of returns. The findings disclose that this manifests that volatility response in the Bangladesh equity market is higher with the arrival of bad information than with any positive information. The results from the TGARCH model also confirm the positive and statistically significant gamma coefficients implying that the asymmetric or leverage effect persists in the Bangladesh equity market for both conventional and Shariah indices. It can be observed that they are asymmetric in the news. Bad information breeds greater return volatility than the good news in the equity market of Bangladesh. Another crucial aspect that we can gather from the TGARCH model is to isolate the impact of bad and good shocks on conditional volatility. Good information to broad market index has a shock of 0.173 , and bad information has a shock of 0.355 (sum of alpha and gamma terms).

On the other hand, good information to the Shariah index has a shock of 0.152 , and bad information has a shock of 0.335 . Interestingly, bad shocks have a similar impact on volatility for both the conventional and the Shariah indices in the Dhaka stock exchange. The results also convey that GARCH effects are more robust than the arch effects for both indices, particularly for the DSEX index, suggesting that volatility effects have more persistence than past shocks impact. That means there are long-term volatility effects in the Bangladesh equity market.

Table 2. Test of Asymmetric Conditional Volatility

\begin{tabular}{ccccc}
\hline & \multicolumn{2}{c}{ DSEX Index } & \multicolumn{2}{c}{ DSES Index } \\
\hline & GED & Student's t & GED & Student's t \\
\hline$\varphi$ & & EGARCH Model & & \\
\hline & -0.72 & -0.63 & -0.96 & -0.95 \\
$\alpha$ (Arch Term) & 0.38 & 0.35 & 0.38 & 0.37 \\
& {$[0.00]$} & {$[0.00]$} & {$[0.00]$} & {$[0.00]$} \\
$\beta$ (Garch Term) & 0.95 & 0.96 & 0.93 & 0.93 \\
& {$[0.00]$} & {$[0.00]$} & {$[0.00]$} & {$[0.00]$} \\
$\lambda$ (Leverage Term) & -0.10 & -0.09 & -0.07 & -0.08 \\
& {$[0.00]$} & {$[0.00]$} & {$[0.00]$} & {$[0.00]$} \\
\hline & & GJR-GARCH & & \\
\hline (Arch Term) & $3.63 \mathrm{E}-06$ & $2.97 \mathrm{E}-06$ & $3.05 \mathrm{E}-06$ & $3.14 \mathrm{E}-06$ \\
$\beta$ (Garch Term) & 0.17 & 0.16 & 0.15 & 0.14 \\
& {$[0.00]$} & {$[0.00]$} & {$[0.00]$} & {$[0.00]$} \\
(Leverage Term) & 0.76 & 0.78 & 0.73 & 0.73 \\
& {$[0.00]$} & {$[0.00]$} & {$[0.00]$} & {$[0.00]$} \\
\hline
\end{tabular}

Note: P-value is given in parentheses. 


\subsection{Test of Long Memory in Conditional Volatility}

The standard conditional volatility models of autoregressive conditional heteroscedasticity (ARCH) and generalized ARCH (GARCH) do only detect the volatility persistence but fail to capture the property of long memory [4]. The Fractionally Integrated GARCH is very pertinent to detect the long-run patterns of returns volatility. Table 3 highlights a more appealing and representative family of Fractionally Integrated GARCH models to ascertain long memory behavior in the conditional variance of two stock indices returns in the context of the Bangladesh equity market, which seems to be sporadic in volatility literature.

The fractionally integrated parameter, $d$, implies the presence of long memory property in conditional volatility of equity returns. The results reveal that the coefficient of long memory remains within the general range of $0<\mathrm{d}<1$ and statistically significant for all the fractionally integrated models (FIGARCH BBM, FIGARCH CHUNG, FIEGARCH, FIAPARCH BBM, FIAPARCH CHUNG, and $\mathrm{HYGARCH}$ ) at 1 percent significance level. The study unequivocally evidences stationary long memory dynamics in conditional volatility for both broad markets index (DSEX) and Shariah-based index (DSES) from the index (DSEX) and Shariah-based index (DSES) from the Bangladesh equity market. Another stimulating feature of fractionally integrated models of FIEGARCH, FIAPARCH BBM \& CHUNG, is capturing both the long memory effects and asymmetric effects of equity returns. The asymmetric coefficient Theta in FIEGARCH is negative, and the coefficient gamma in FIAPARCH BBM and CHUNG is positive, and all these leverage coefficients are statistically significant. Findings are consistent with what we find from univariate asymmetric GARCH models in the earlier part of our study. The results of both long memory and asymmetric effects in conditional volatility for Shariah-based index (DSES) under all fractionally integrated GARCH models are displayed in Table 4. Results indicate that there are also asymmetric shocks on conditional volatility that prevail for both stock indices returns.

Table 3. Test of Long Memory in Conditional Volatility for DSEX Index

\begin{tabular}{|c|c|c|c|c|c|c|}
\hline & $\begin{array}{c}\text { FIGARCH } \\
\text { BBM }\end{array}$ & $\begin{array}{c}\text { FIGARCH } \\
\text { CHUNG }\end{array}$ & FIEGARH & $\begin{array}{c}\text { FIAPARCH } \\
\text { BBM }\end{array}$ & $\begin{array}{l}\text { FIAPARCH } \\
\text { CHUNG }\end{array}$ & HYGARCH \\
\hline $\operatorname{Cst}(\mathrm{M})$ & $\begin{array}{c}0.00 \\
{[0.00]}\end{array}$ & $\begin{array}{c}0.00 \\
{[0.00]}\end{array}$ & $\begin{array}{c}0.00 \\
{[0.03]}\end{array}$ & $\begin{array}{c}0.00 \\
{[0.01]}\end{array}$ & $\begin{array}{c}0.00 \\
{[0.01]}\end{array}$ & $\begin{array}{c}0.00 \\
{[0.00]}\end{array}$ \\
\hline $\operatorname{Cst}(\mathrm{V})$ & $\begin{array}{c}0.04 \\
{[0.00]}\end{array}$ & $\begin{array}{c}5.58 \\
{[0.01]}\end{array}$ & $\begin{array}{c}-91049 \\
{[0.00]}\end{array}$ & $\begin{array}{c}0.32 \\
{[0.37]}\end{array}$ & $\begin{array}{l}40.49 \\
{[0.64]}\end{array}$ & $\begin{array}{c}0.04 \\
{[0.02]}\end{array}$ \\
\hline d-Figarch & $\begin{array}{c}0.51 \\
{[0.00]}\end{array}$ & $\begin{array}{c}0.56 \\
{[0.00]}\end{array}$ & $\begin{array}{c}0.52 \\
{[0.00]}\end{array}$ & $\begin{array}{c}0.49 \\
{[0.00]}\end{array}$ & $\begin{array}{c}0.48 \\
{[0.00]}\end{array}$ & $\begin{array}{c}0.51 \\
{[0.00]}\end{array}$ \\
\hline$\alpha$ & $\begin{array}{c}0.09 \\
{[0.33]}\end{array}$ & $\begin{array}{c}0.08 \\
{[0.32]}\end{array}$ & $\begin{array}{c}0.26 \\
{[0.32]}\end{array}$ & $\begin{array}{c}0.10 \\
{[0.24]}\end{array}$ & $\begin{array}{c}0.07 \\
{[0.39]}\end{array}$ & $\begin{array}{c}0.08 \\
{[0.37]}\end{array}$ \\
\hline$\beta$ & $\begin{array}{c}0.37 \\
{[0.00]}\end{array}$ & $\begin{array}{c}0.41 \\
{[0.00]}\end{array}$ & $\begin{array}{c}0.35 \\
{[0.09]}\end{array}$ & $\begin{array}{c}0.39 \\
{[0.00]}\end{array}$ & $\begin{array}{c}0.36 \\
{[0.00]}\end{array}$ & $\begin{array}{c}0.37 \\
{[0.00]}\end{array}$ \\
\hline $\begin{array}{l}\Theta_{1} \\
\Theta_{2}\end{array}$ & & & $\begin{array}{c}-0.08 \\
{[0.00]} \\
0.35 \\
{[0.00]}\end{array}$ & & & \\
\hline$\gamma$ & & & & $\begin{array}{c}0.20 \\
(0.00)\end{array}$ & $\begin{array}{c}0.21 \\
(0.00)\end{array}$ & \\
\hline$\delta$ & & & & $\begin{array}{c}1.67 \\
{[0.00]}\end{array}$ & $\begin{array}{c}1.55 \\
{[0.00]}\end{array}$ & \\
\hline Log Alpha & & & & & & $\begin{array}{l}0.019 \\
{[0.57]}\end{array}$ \\
\hline Student (DF) & $\begin{array}{c}7.64 \\
{[0.00]} \\
\end{array}$ & $\begin{array}{c}7.46 \\
{[0.00]} \\
\end{array}$ & $\begin{array}{c}7.78 \\
{[0.00]} \\
\end{array}$ & $\begin{array}{c}8.22 \\
{[0.00]} \\
\end{array}$ & $\begin{array}{c}8.18 \\
{[0.00]} \\
\end{array}$ & $\begin{array}{c}7.51 \\
{[0.00]} \\
\end{array}$ \\
\hline
\end{tabular}

Note: P-value is given in parentheses. All models are estimated using OxMetrics 
Table 4. Test of Long Memory in Conditional Volatility

\begin{tabular}{|c|c|c|c|c|c|c|}
\hline & $\begin{array}{c}\text { FIGARCH } \\
\text { BBM }\end{array}$ & $\begin{array}{c}\text { FIGARCH } \\
\text { CHUNG } \\
\end{array}$ & FIEGARCH & $\begin{array}{c}\text { FIAPARCH } \\
\text { BBM } \\
\end{array}$ & $\begin{array}{c}\text { FIAPARCH } \\
\text { CHUNG }\end{array}$ & HYGARCH \\
\hline Cst (M) & $\begin{array}{c}0.00 \\
{[0.45]}\end{array}$ & $\begin{array}{c}0.00 \\
{[0.48]}\end{array}$ & $\begin{array}{l}-0.00 \\
{[0.83]}\end{array}$ & $\begin{array}{c}0.00 \\
{[0.92]}\end{array}$ & $\begin{array}{c}0.00 \\
{[0.82]}\end{array}$ & $\begin{array}{c}0.00 \\
{[0.44]}\end{array}$ \\
\hline Cst (V) & $\begin{array}{c}2.72 \\
{[0.00]}\end{array}$ & $\begin{array}{l}271.27 \\
{[0.00]}\end{array}$ & $\begin{array}{l}-0.00 \\
{[1.00]}\end{array}$ & $\begin{array}{l}396.70 \\
{[0.00]}\end{array}$ & $\begin{array}{c}1748.87 \\
{[0.00]}\end{array}$ & $\begin{array}{c}3.41 \\
{[0.00]}\end{array}$ \\
\hline d-Figarch & $\begin{array}{c}1.00 \\
{[0.00]}\end{array}$ & $\begin{array}{c}0.59 \\
{[0.00]}\end{array}$ & $\begin{array}{c}0.73 \\
{[0.00]}\end{array}$ & $\begin{array}{c}0.67 \\
{[0.00]}\end{array}$ & $\begin{array}{c}0.47 \\
{[0.00]}\end{array}$ & $\begin{array}{c}1.00 \\
{[0.00]}\end{array}$ \\
\hline$\alpha$ & $\begin{array}{c}0.00 \\
{[1.00]}\end{array}$ & $\begin{array}{l}0.131 \\
{[0.08]}\end{array}$ & $\begin{array}{l}-0.50 \\
{[0.00]}\end{array}$ & $\begin{array}{c}0.14 \\
{[0.04}\end{array}$ & $\begin{array}{c}0.17 \\
{[0.01]}\end{array}$ & $\begin{array}{c}0.00 \\
{[1.00]}\end{array}$ \\
\hline$\beta$ & $\begin{array}{c}0.71 \\
{[0.00]}\end{array}$ & $\begin{array}{c}0.49 \\
{[0.00]}\end{array}$ & $\begin{array}{c}0.78 \\
{[0.00]}\end{array}$ & $\begin{array}{c}0.62 \\
{[0.00]}\end{array}$ & $\begin{array}{c}0.45 \\
{[0.00]}\end{array}$ & $\begin{array}{c}0.70 \\
{[0.00]}\end{array}$ \\
\hline $\begin{array}{l}\Theta_{1} \\
\Theta_{2}\end{array}$ & & & $\begin{array}{c}-0.07 \\
{[0.00]} \\
0.62 \\
{[0.00]}\end{array}$ & & & \\
\hline $\begin{array}{l}\gamma \\
\delta\end{array}$ & & & & $\begin{array}{c}0.22 \\
{[0.00]} \\
1.09 \\
{[0.00]}\end{array}$ & $\begin{array}{c}0.22 \\
{[0.00]} \\
1.55 \\
{[0.00]}\end{array}$ & \\
\hline Log Alpha & & & & & & $\begin{array}{l}-0.04 \\
{[0.18]} \\
\end{array}$ \\
\hline Student (DF) & $\begin{array}{c}9.11 \\
{[0.00]}\end{array}$ & $\begin{array}{l}10.65 \\
{[0.00]}\end{array}$ & $\begin{array}{c}6.26 \\
{[0.00]}\end{array}$ & $\begin{array}{l}10.60 \\
{[0.00]}\end{array}$ & $\begin{array}{l}10.94 \\
{[0.00]}\end{array}$ & $\begin{array}{c}9.71 \\
{[0.00]}\end{array}$ \\
\hline
\end{tabular}

Note: P-value is given in parentheses. All models are estimated using OxMetrics 7.

Results appear in Table 4 indicate that the fractional differencing parameter $d$ provides the presence of long memory property for DSES index returns in the case of FIGARCH CHUNG, FIEGARCH, FIAPRACH BBM, and CHUNG models (as $0<\mathrm{d}<1$ ) and confirmed by the statistically significant $p$ values. The long memory effect is strongly evidenced for the FIAPARCH CHUNG model, where $\mathrm{d} \sim(0,0.5)$ ensures a stationary covariance process.

On the other hand, the leverage effects (asymmetric response to positive and negative shocks) are also present for the DSES index confirmed by the statistically significant negative coefficient of theta in FIEGARCH and positive coefficients of gamma in both FIAPARCH BBM \& CHUNG models, respectively. The findings are indistinguishable from the results that we found in the case of the DSEX index.

\subsection{The Test for Model Misspecification}

One of the traits of the present study is to address the model specification tests for both stock indices returns.

Table 5 presents diagnostic tests' results under all fractionally integrated GARCH models for DSEX (broad market index). Results disclose that we fail to reject the null hypothesis of no serial correlation under Q statistics on squared residuals and the null hypothesis of no heteroscedasticity using ARCH LM test statistics for all the models. This implies that all the fractionally integrated GARCH models are fairly specified and fit for modeling the index returns series. Another good part of the study is to diagnose misspecification tests of the conditional volatility equation based on the news impact curve. The results from sign bias, positive and negative size bias and joint tests are not statistically significant, meaning that we decline to reject the null hypothesis that the volatility model is fairly correct. Similar findings are affirmed for the Shariah Index (DSES) presented in Table 6.

All the fractionally integrated GARCH specifications do not suffer from heteroscedasticity problems, and these models are fairly specified for modeling conditional volatility, but some of the models experience autocorrelation problems as authenticated by the $Q$ statistics results. Based on the diagnostic statistics, we make sure that modeling the conditional volatility using various fractionally integrated GARCH specifications does perform better in terms of benchmark market index relative to the Shariah index. Lastly, we select FIEGARCH specification outperforms other fractionally integrated GARCH specifications in modeling DSEX index returns, and FIAPARCH BBM represents the best specification in modeling Shariah index returns based on Log-likelihood as well as both Akaike Information Criterion (AIC) a Schwartz Information Criterion (SIC). It is seen that both the best performing specifications can capture the presence of long memory and asymmetric effects properties together, which are the primary concern of the current study. 
New Evidence from Family of FIGARCH Models

Table 5. Fractionally Integrated GARCH models for DSEX Index

\begin{tabular}{|c|c|c|c|c|c|c|}
\hline & $\begin{array}{c}\text { FIGARCH } \\
\text { BBM }\end{array}$ & $\begin{array}{c}\text { FIGARCH } \\
\text { CHUNG }\end{array}$ & FIEGARCH & $\begin{array}{c}\text { FIAPARCH } \\
\text { BBM }\end{array}$ & $\begin{array}{c}\text { FIAPARCH } \\
\text { CHUNG } \\
\end{array}$ & HYGARCH \\
\hline \multicolumn{7}{|c|}{ Q Stat on Squared Residuals } \\
\hline $\mathrm{Q}(5)$ & $\begin{array}{c}8.10 \\
{[0.04]}\end{array}$ & $\begin{array}{c}5.80 \\
{[0.12]}\end{array}$ & $\begin{array}{c}8.04 \\
{[0.05]}\end{array}$ & $\begin{array}{l}12.13 \\
{[0.01]}\end{array}$ & $\begin{array}{l}12.46 \\
{[0.01]}\end{array}$ & $\begin{array}{c}7.47 \\
{[0.06]}\end{array}$ \\
\hline $\mathrm{Q}(10)$ & $\begin{array}{l}14.70 \\
{[0.07]}\end{array}$ & $\begin{array}{c}9.06 \\
{[0.34]}\end{array}$ & $\begin{array}{l}16.34 \\
{[0.04]}\end{array}$ & $\begin{array}{l}20.66 \\
{[0.01]} \\
\end{array}$ & $\begin{array}{l}16.04 \\
{[0.04]}\end{array}$ & $\begin{array}{l}13.76 \\
{[0.09]} \\
\end{array}$ \\
\hline \multicolumn{7}{|c|}{ Volatility Specification Test based on News Impact Curve: } \\
\hline Sign Bias & $\begin{array}{c}0.45 \\
{[0.65]}\end{array}$ & $\begin{array}{c}0.12 \\
{[0.90]}\end{array}$ & $\begin{array}{c}0.22 \\
{[0.82]}\end{array}$ & $\begin{array}{c}0.37 \\
{[0.72[}\end{array}$ & $\begin{array}{l}0.63 \\
{[0.52]}\end{array}$ & $\begin{array}{c}0.41 \\
{[0.68]}\end{array}$ \\
\hline Negative Size Bias & $\begin{array}{c}1.00 \\
{[0.32]}\end{array}$ & $\begin{array}{c}2.01 \\
{[0.04]}\end{array}$ & $\begin{array}{c}1.67 \\
{[0.10]}\end{array}$ & $\begin{array}{c}1.18 \\
{[0.24]}\end{array}$ & $\begin{array}{c}1.60 \\
{[0.10]}\end{array}$ & $\begin{array}{c}1.52 \\
{[0.13]}\end{array}$ \\
\hline Positive Size Bias & $\begin{array}{c}0.97 \\
{[0.33]}\end{array}$ & $\begin{array}{c}0.64 \\
{[0.52]}\end{array}$ & $\begin{array}{c}2.34 \\
{[0.02]}\end{array}$ & $\begin{array}{c}0.49 \\
{[0.62]}\end{array}$ & $\begin{array}{c}0.73 \\
{[0.47]}\end{array}$ & $\begin{array}{c}0.57 \\
{[0.57]}\end{array}$ \\
\hline Joint Test & $\begin{array}{c}5.62 \\
{[0.13]} \\
\end{array}$ & $\begin{array}{r}8.38 \\
{[0.04]} \\
\end{array}$ & $\begin{array}{r}8.29 \\
{[0.04]} \\
\end{array}$ & $\begin{array}{c}1.63 \\
{[0.65]} \\
\end{array}$ & $\begin{array}{r}3.16 \\
{[0.37]} \\
\end{array}$ & $\begin{array}{r}6.59 \\
{[0.09]} \\
\end{array}$ \\
\hline \multicolumn{7}{|c|}{ ARCH Test Statistics } \\
\hline ARCH 1-2 test: & $\begin{array}{c}1.85 \\
{[0.16]}\end{array}$ & $\begin{array}{c}0.52 \\
{[0.59]}\end{array}$ & $\begin{array}{c}2.23 \\
{[0.11]}\end{array}$ & $\begin{array}{c}1.05 \\
{[0.35]}\end{array}$ & $\begin{array}{c}0.34 \\
{[0.72]}\end{array}$ & $\begin{array}{c}1.15 \\
{[0.32]}\end{array}$ \\
\hline ARCH 1-5 test: & $\begin{array}{c}1.54 \\
{[0.17]}\end{array}$ & $\begin{array}{c}1.12 \\
{[0.35]}\end{array}$ & $\begin{array}{c}1.61 \\
{[0.15]}\end{array}$ & $\begin{array}{c}2.26 \\
{[0.05]}\end{array}$ & $\begin{array}{c}2.43 \\
{[0.03]}\end{array}$ & $\begin{array}{c}1.41 \\
{[0.22]}\end{array}$ \\
\hline AIC & -7.17 & -7.17 & -7.09 & -7.18 & -7.18 & -7.17 \\
\hline SIC & -7.14 & -7.15 & -7.07 & -7.15 & -7.15 & -7.15 \\
\hline Log-Likelihood & 5905.04 & 5899.85 & 5841.8 & 5913.63 & 5913.27 & 5906.26 \\
\hline
\end{tabular}

Note: P-value is given in parentheses. All models are estimated using OxMetrics 7.

Table 6. Fractionally Integrated GARCH models for Shariah Index

\begin{tabular}{|c|c|c|c|c|c|c|}
\hline & $\begin{array}{c}\text { FIGARCH } \\
\text { BBM }\end{array}$ & $\begin{array}{c}\text { FIGARCH } \\
\text { CHUNG }\end{array}$ & FIEGARCH & $\begin{array}{c}\text { FIAPARCH } \\
\text { BBM } \\
\end{array}$ & $\begin{array}{l}\text { FIAPARCH } \\
\text { CHUNG } \\
\end{array}$ & HYGARCH \\
\hline \multicolumn{7}{|c|}{ Q Stat on Squared Residuals } \\
\hline $\mathrm{Q}(5)$ & $\begin{array}{c}0.06 \\
{[0.99]}\end{array}$ & $\begin{array}{c}0.07 \\
{[0.99]}\end{array}$ & $\begin{array}{c}0.03 \\
{[0.99]}\end{array}$ & $\begin{array}{c}0.05 \\
{[0.99]}\end{array}$ & $\begin{array}{c}0.05 \\
{[0.99]}\end{array}$ & $\begin{array}{c}0.06 \\
{[0.99]}\end{array}$ \\
\hline Q (10) & $\begin{array}{c}0.22 \\
{[0.99]} \\
\end{array}$ & $\begin{array}{c}0.23 \\
{[0.99]} \\
\end{array}$ & $\begin{array}{c}0.20 \\
{[0.99]} \\
\end{array}$ & $\begin{array}{c}0.21 \\
{[0.99]} \\
\end{array}$ & $\begin{array}{c}0.21 \\
{[0.99]} \\
\end{array}$ & $\begin{array}{c}0.23 \\
{[0.99]} \\
\end{array}$ \\
\hline \multicolumn{7}{|c|}{ Volatility Specification Test based on News Impact Curve: } \\
\hline Sign Bias & $\begin{array}{c}1.24 \\
{[0.22]}\end{array}$ & $\begin{array}{c}1.17 \\
{[0.24]}\end{array}$ & $\begin{array}{c}0.81 \\
{[0.42]}\end{array}$ & $\begin{array}{c}1.00 \\
{[0.31]}\end{array}$ & $\begin{array}{c}1.02 \\
{[0.31]}\end{array}$ & $\begin{array}{c}1.16 \\
{[0.24]}\end{array}$ \\
\hline Negative Size Bias & $\begin{array}{c}0.62 \\
{[0.54]}\end{array}$ & $\begin{array}{c}0.59 \\
{[0.55]}\end{array}$ & $\begin{array}{c}0.36 \\
{[0.72]}\end{array}$ & $\begin{array}{c}0.68 \\
{[0.50]}\end{array}$ & $\begin{array}{c}0.66 \\
{[0.51}\end{array}$ & $\begin{array}{c}0.60 \\
{[0.55]}\end{array}$ \\
\hline Positive Size Bias & $\begin{array}{c}0.31 \\
{[0.76]}\end{array}$ & $\begin{array}{c}0.34 \\
{[0.73]}\end{array}$ & $\begin{array}{c}0.15 \\
{[0.88]}\end{array}$ & $\begin{array}{c}0.13 \\
{[0.89]}\end{array}$ & $\begin{array}{c}0.12 \\
{[0.90]}\end{array}$ & $\begin{array}{c}0.34 \\
{[0.73]}\end{array}$ \\
\hline Joint Test & $\begin{array}{c}2.47 \\
{[0.48]}\end{array}$ & $\begin{array}{c}2.33 \\
{[0.51]}\end{array}$ & $\begin{array}{c}1.00 \\
{[0.80]}\end{array}$ & $\begin{array}{c}1.42 \\
{[0.70]}\end{array}$ & $\begin{array}{c}1.43 \\
{[0.70}\end{array}$ & $\begin{array}{c}2.29 \\
{[0.51]}\end{array}$ \\
\hline \multicolumn{7}{|c|}{ ARCH LM Test Statistics: } \\
\hline ARCH $1-2$ test: & $\begin{array}{c}0.02 \\
{[0.98]}\end{array}$ & $\begin{array}{c}0.02 \\
{[0.98]}\end{array}$ & $\begin{array}{c}0.01 \\
{[0.99]}\end{array}$ & $\begin{array}{c}1.05 \\
{[0.35]}\end{array}$ & $\begin{array}{c}0.02 \\
{[0.98]}\end{array}$ & $\begin{array}{c}0.01 \\
{[0.99]}\end{array}$ \\
\hline ARCH 1-5 test: & $\begin{array}{l}0.012 \\
{[1.00]}\end{array}$ & $\begin{array}{c}0.01 \\
{[0.99]}\end{array}$ & $\begin{array}{c}0.01 \\
{[1.00]}\end{array}$ & $\begin{array}{c}2.26 \\
{[0.05]}\end{array}$ & $\begin{array}{c}0.01 \\
{[1.000]}\end{array}$ & $\begin{array}{c}0.02 \\
{[1.00]}\end{array}$ \\
\hline AIC & -6.36 & -6.36 & -6.38 & -6.37 & -6.37 & -6.36 \\
\hline SIC & -6.35 & -6.35 & -6.36 & -6.36 & -6.36 & -6.35 \\
\hline Log-Likelihood & 12536.35 & 12536.6 & 12573.7 & 12560.0 & 12564.63 & 12536.54 \\
\hline
\end{tabular}

Note: P-value is given in parentheses. All models are estimated using Ox Metrics 7. 


\section{Conclusions}

This paper models the conditional volatility of equity returns in Bangladesh to scrutinize the presence of the risk-return tradeoff, asymmetric effects, and long memory property covering from July 1, 2004 to December 31, 2020. We focus on two major equity market indices: the Dhaka Stock Exchange benchmark index (DSEX) and the Shariah Index (DSES). We begin the paper by studying the risk-return tradeoff in the time-varying volatility using symmetric GARCH in the Mean model and find that the risk premium coefficient in conditional mean becomes statistically significant. Thus, there is no risk premium observed for both indices, which manifests a very unusual finding that investments in the Bangladesh equity market may not constitute any risky element. This finding seems to be inconsistent with asset pricing theories in finance.

We also investigate the presence of the leverage effects and long memory behavior in the conditional volatility of DSEX and DESS indices return series. Asymmetric univariate conditional volatility models of EGARCH and GJR-GARCH are employed to estimate under general error and student-t distributions methods to model the leverage effect phenomenon. The results from both models reveal that leverage effects persist in the Bangladesh equity market for both the conventional and the Shariah indices under both estimation methods implying that volatility response is higher with the arrival of bad information than it does with any positive information. But it is interestingly confirmed that bad shocks have a similar impact on volatility for both conventional and Shariah indices.

This paper applies a family of fractionally integrated GARCH specifications to model the long memory property in conditional volatility, which may hardly ever present in existing volatility literature. The results from all fractionally integrated GARCH models substantially document the presence of long memory behavior in conditional volatility for both DSEX and DSES indices, which is supported by the statistically significant value of the fractional differencing parameter. Another fascinating finding we report in the study on the bias of AIC and SIC and $\log$-likelihood criteria that FIEGARCH is distinguished as a fairly developed specification for modeling the DSEX returns, and it is found to be FIAPARCH CHUNG in the case of DSES index. Thus, the study registers strong evidence in favor of asymmetric response and long memory property in conditional volatility of DSEX and DSES indices in the Bangladesh equity market that ultimately rejects the weak-form efficient hypothesis. The findings have immense implications for researchers, retail and wholesale investors, financial analysts, and other market players to make informed equity investment decisions. Results, in particular, are important to the regulator as the Bangladesh equity market is characterized by some idiosyncratic behaviors like inadequate trading regulations and monitoring framework, shortage of capital, manipulation on the part of wealthy and influential investors, insider trading, etc. The regulatory authority can play a big role in noticing the findings from the study and initiating the necessary actions to improve market efficiency. Advanced technology-equipped trading surveillance systems can be ensured to deal with trading manipulation by order size \& volume and other trading irregularities observed in the market. It will provide greater transparency in the share trading process and reduce the opportunities present for informed investors to gain abnormal profits. The regulatory body may also emphasize improving the relative liquidity (enhancing the breath, depth, and market resilience dimensions of liquidity) through a conducive monetary policy to be implemented by the central bank to make the Bangladesh equity market more efficient. Liquidity can be treated as a building block of restoring market efficiency for any emerging market [53] - [55]. A more liquid market can cushion the volatility of the market created by any abrupt shifts in investors' risk preferences.

Further research can be initiated to investigate these volatility phenomena for the equity markets in South Asia.

\section{REFERENCES}

[1] Zabiulla, "Volatility Clustering and Leverage Effect in the Indian Forex Market," Glob. Bus. Rev., vol. 16, no. 5, pp. 785-799, 2015, doi: 10.1177/0972150915591453.

[2] J. Beran and M. Schützner, "The effect of long memory in volatility on location estimation," Sankhya Indian J. Stat., vol. 70, no. 1, pp. 84-112, 2008.

[3] C. Hill, "L ong memory in the Greek stock market," 2000.

[4] Y. Lee, L. A. Nunes Amaral, D. Canning, M. Meyer, and H. E. Stanley, "Universal features in the growth dynamics of complex organizations," Phys. Rev. Lett., vol. 81, no. 15, pp. 3275-3278, 1998, doi: 10.1103/PhysRevLett.81.3275.

[5] S. Sadique and P. Silvapulle, "Long-term memory in stock market returns: international evidence," Int. J. Financ. Econ., vol. 6, no. 1, pp. 59-67, 2001, doi: 10.1002/ijfe.143.

[6] S. Rastogi, "The financial crisis of 2008 and stock market volatility - Analysis and impact on emerging economies pre and post crisis," Afro-Asian J. Financ. Account., vol. 4, no. 4, pp. 443-459, 2014, doi: 10.1504/AAJFA.2014.067017.

[7] K. Saleem, "Modeling long memory in the Russian stock market: Evidence from major Sectoral indices," J. Appl. Bus. Res., vol. 30, no. 2, pp. 567-573, 2014, doi: 10.19030/jabr.v30i2.8426.

[8] B. Bagchi and A. Bhunia, D Dandapat, "Analysis of volatility and leverage effecting selected stock markets" Indian Accounting Review, vol. 23, no. 1, 2019.

[9] R. T. Baillie, T. Bollerslev, and H. O. Mikkelsen, 
"Fractionally integrated generalized autoregressive conditional heteroskedasticity," J. Econom., vol. 74, no. 1, pp. 3-30, Sep. 1996, doi: 10.1016/S0304-4076(95)01749-6.

[10] T. E. Society, "Conditional Heteroskedasticity in Asset Returns: A New Approach Author (s): Daniel B. Nelson Published by: The Econometric Society CONDITIONAL HETEROSKEDASTICITY IN ASSET RETURNS : A NEW APPROACH," vol. 59, no. 2, pp. 347-370, 2014.

[11] L. R. GLOSTEN, R. JAGANNATHAN, and D. E. RUNKLE, "On the Relation between the Expected Value and the Volatility of the Nominal Excess Return on Stocks," J. Finance, vol. 48, no. 5, pp. 1779-1801, 1993, doi: 10.1111/j.1540-6261.1993.tb05128.x.

[12] R. L. Engle and T. Bolerslev, "Ectrev_86.Pdf." 1986.

[13] R. T. Baillie, "Long memory processes and fractional integration in econometrics," J. Econom., vol. 73, no. 1, pp. 5-59, 1996, doi: 10.1016/0304-4076(95)01732-1.

[14] T. Bollerslev and H. O. Mikkelsen, "Modeling and pricing long memory in stock market volatility," J. Econom., vol. 73, no. 1, pp. 151-184, Jul. 1996, doi: 10.1016/0304-4076(95)01736-4.

[15] Y. K. Tse, "The conditional heteroscedasticity of the yen-dollar exchange rate," J. Appl. Econom., vol. 13, no. 1, pp. 49-55, 1998, doi: 10.1002/(SICI)10991255(199801/02 )13:1<49::AID-JAE459>3.0.CO;2-O.

[16] A. K. Mishra, N. Swain, and D. Malhotra, "Volatility Spillover between Stock and Foreign Exchange Markets: Indian Evidence," Int. J. Bus., vol. 12, no. 3, p. 343, 2007.

[17] S. Yang, "Price and Volatility Spillovers between Stock Prices and Exchange Rates: Empirical Evidence from the G-7 Countries,” Int. J. Bus. Econ., vol. 3, no. 2, pp. 139-153, 2004.

[18] L. de las N. Morales, "Volatility Spillovers between Equity and Currency Markets: Eviderice from Major Latin American Countries," Cuad. Econ., vol. 45, no. 132, pp. 185-215, Nov. 2008, doi: 10.4067/S0717-68212008000200 002.

[19] P. Panda and M. Deo, "Asymmetric cross-market volatility spillovers: evidence from Indian equity and foreign exchange markets," Decision, vol. 41, no. 3, pp. 261-270, 2014, doi: 10.1007/s40622-014-0044-2.

[20] K. Jebran and A. Iqbal, "Examining volatility spillover between Asian countries' stock markets," China Financ. Econ. Rev., vol. 4, no. 1, 2016, doi: 10.1186/s40589-016-0031-1.

[21] S. Mabrouk, "Forecasting Financial Assets Volatility Using Integrated GARCH-Type Models: International Evidence," J. Financ. Econ. Vol. 4, 2016, Pages 54-62, vol. 4, no. 2, pp. 54-62, Apr. 2016, doi: 10.12691/JFE-4-2-3.

[22] M. M. Ali, A. K. Tiwari, and N. Raza, "Impact of return on long-memory data set of volatility of Dhaka Stock Exchange market with the role of financial institutions: An empirical analysis," Banks Bank Syst., vol. 12, no. 3, pp. 48-60, 2017, doi: 10.21511/bbs.12(3).2017.04.

[23] W. E. Herbert, G. O. Ugwuanyi, and E. I. Nwaocha, "Volatility Clustering, Leverage Effects and Risk-Return Trade-Off in the Nigerian Stock Market," no. January, 2019, doi: 10.12691/jfe-7-1-1.

[24] K. R. French, G. W. Schwert, and R. F. Stambaugh, "Expected stock returns and volatility," J. financ. econ., vol. 19, no. 1, pp. 3-29, 1987, doi: 10.1016/0304-405X(87)90026-2.

[25] C. Lundblad, "The risk return tradeoff in the long run: 1836-2003," J. financ. econ., vol. 85, no. 1, pp. 123-150, 2007, doi: 10.1016/j.jfineco.2006.06.003.

[26] N. Ahmad, R. Raheem Ahmed, J. Vveinhardt, and D. Streimikiene, "Empirical analysis of stock returns and volatility: evidence from Asian stock markets," Technol. Econ. Dev. Econ., vol. 22, no. 6, pp. 808-829, 2016, doi: 10.3846/20294913.2016.1213204.

[27] A. T. Mollik and M. K. Bepari, "Risk-Return Trade-Off in emerging markets: Evidence from Dhaka Stock Exchange Bangladesh," Australas. Accounting, Bus. Financ. J., vol. 9, no. 1, pp. 71-88, 2015, doi: 10.14453/aabfj.v9i1.6.

[28] S. Mollah and A. Mobarek, "Market volatility across countries - evidence from international markets," Stud. Econ. Financ., vol. 26, no. 4, pp. 257-274, 2009, doi: $10.1108 / 10867370910995717$.

[29] H. Al Refai, M. Abdelaziz Eissa, and R. Zeitun, "Asymmetric volatility and conditional expected returns: Evidence from emerging market sectors," Int. J. Emerg. Mark., vol. 12, no. 2, pp. 335-351, 2017, doi: 10.1108/IJoEM-12-2015-0255.

[30] M. Albaity and R. Ahmad, "Return performance, leverage effect, and volatility spillover in Islamic stock indices evidence from DJIMI, FTSEGII and KLSI," Invest. Manag. Financ. Innov., vol. 8, no. 3, pp. 161-171, 2011.

[31] S. Kuttu, "Modelling long memory in volatility in sub-Saharan African equity markets," Res. Int. Bus. Financ., vol. 44, no. July, pp. 176-185, 2018, doi: 10.1016/j.ribaf.2017.07.073.

[32] F. Black, "The pricing of commodity contracts," J. financ. econ., vol. 3, no. 1-2, pp. 167-179, Jan. 1976, doi: 10.1016/0304-405X(76)90024-6.

[33] A. A. Christie, "The stochastic behavior of common stock variances. Value, leverage and interest rate effects," J. financ. econ., vol. 10, no. 4, pp. 407-432, 1982, doi: 10.1016/0304-405X(82)90018-6.

[34] A. Bhunia and S. Ganguly, "An assessment of volatility and leverage effect before and during the period of Covid-19: a study of selected international stock markets," Int. J. Financ. Serv. Manag., vol. 10, no. 2, p. 113, 2020, doi: 10.1504/ijfsm.2020.110224.

[35] S. Chon and J. Kim, "Does the Financial Leverage Effect Depend on Volatility Regimes?," Financ. Res. Lett., p. 101600, 2020, doi: 10.1016/j.frl.2020.101600.

[36] T. Walther, "Expected shortfall in the presence of asymmetry and long memory," Pacific Account. Rev., vol. 29, no. 2, pp. 132-151, 2017, doi: 10.1108/par-06-2016-0063.

[37] S. R. Bentes, R. Menezes, and D. A. Mendes, "Long memory and volatility clustering: Is the empirical evidence consistent across stock markets?," Phys. A Stat. Mech. its Appl., vol. 387, no. 15, pp. 3826-3830, 2008, doi: 


\subsection{6/j.physa.2008.01.046.}

[38] T. Choudhry, "The long memory of time-varying beta: Examination of three emerging asian stock markets," Manag. Financ., vol. 27, no. 1-2, pp. 5-23, 2001, doi: 10.1108/03074350110767475.

[39] C. Floros, S. Jaffry, and G. Valle Lima, "Long memory in the Portuguese stock market," Stud. Econ. Financ., vol. 24, no. 3, pp. 220-232, 2007, doi: 10.1108/108673707108174 00 .

[40] C. M. Hurvich, E. Moulines, and P. Soulier, "Estimating long memory in volatility," Econometrica, vol. 73, no. 4, pp. 1283-1328, 2005, doi: 10.1111/j.1468-0262.2005.00616.x.

[41] D. V. Vougas, "Analysing long memory and volatility of returns in the Athens stock exchange," Appl. Financ. Econ., vol. 14, no. 6, pp. 457-460, 2004, doi: $10.1080 / 09603100410001673694$.

[42] G. M. Caporale, M. Karanasos, S. Yfanti, and A. Kartsaklas, 'Investors' trading behaviour and stock market volatility during crisis periods: A dual long-memory model for the Korean Stock Exchange,” Int. J. Financ. Econ., no. January 2019, pp. 1-21, 2020, doi: 10.1002/ijfe.2024.

[43] R. A. Lamouchi, "Long Memory and Stock Market Efficiency: Case of Saudi Arabia," Int. J. Econ. Financ. Issues, vol. 10, no. 3, pp. 29-34, 2020, doi: 10.32479/ijefi.9568.

[44] A. I. Lawal et al., "Examining the effects of oil price long memory and exchange rate long memory on stock market behavior in Nigeria,” Int. J. Energy Econ. Policy, vol. 10, no. 4, pp. 430-436, 2020, doi: 10.32479/ijeep.9643.

[45] S. Lecturer and S. Lanka, "Testing for Long Memory in Stock Market Returns: Evidence from Sri Lanka: A Fractional Integration Approach,” 2020.

[46] K. Mokni and F. Mansouri, "Conditional dependence between international stock markets: A long memory GARCH-copula model approach," J. Multinatl. Financ. Manag., vol. 42-43, pp. 116-131, 2017, doi: 10.1016/j.mulfin.2017.10.006.
[47] G. Duppati, A. S. Kumar, F. Scrimgeour, and L. Li, "Long memory volatility in Asian stock markets," Pacific Account. Rev., vol. 29, no. 3, pp. 423-442, 2017, doi: 10.1108/par-02-2016-0009.

[48] T. A. Abdul Manap and S. H. Kassim, "Long memory properties and asymmetric effects of emerging equity market: Evidence from Malaysia," J. Risk Financ., vol. 12, no. 5, pp. 356-370, 2011, doi: 10.1108/152659411111761 09.

[49] N. Crato and P. J. F. de Lima, "Long - memory and Nonlinearity: A Time Series Analysis of Stock Returns and Volatilities," Manag. Financ., vol. 20, no. 2, pp. 49-67, 1994, doi: 10.1108/eb018463.

[50] T. E. Society, "Conditional Heteroskedasticity in Asset Returns: A New Approach Author (s): Daniel B. Nelson Published by: The Econometric Society Stable URL: http://www.jstor.org/stable/2938260 Accessed :04-06-2016 14 : 12 UTC Your use of the JSTOR archive indica," vol. 59, no. 2, pp. 347-370, 2016.

[51] J. M. Zakoian, "Threshold heteroskedastic models," J. Econ. Dyn. Control, vol. 18, no. 5, pp. 931-955, Sep. 1994, doi: 10.1016/0165-1889(94)90039-6.

[52] J. Davidson, "Moment and Memory Properties of Linear Conditional Heteroscedasticity Models, and a New Model," J. Bus. Econ. Stat., vol. 22, no. 1, pp. 16-29, 2004, doi: $10.1198 / 073500103288619359$.

[53] T. Chordia, R. Roll, and A. Subrahmanyam, "Liquidity and market efficiency," J. financ. econ., vol. 87, no. 2, pp. 249 268, Feb. 2008, doi: 10.1016/J.JFINECO.2007.03.005.

[54] R. Mwesigwa, S. Tumwine, and E. R. Atwine, "The role of market liquidity, information efficiency on stock market performance: Empirical evidence from Uganda stock exchange," African J. Bus. Manag., vol. 7, no. 37, pp. 3781-3789, Oct. 2013, doi: 10.5897/AJBM11.2115.

[55] A. S. Yang and A. Pangastuti, "Stock market efficiency and liquidity: The Indonesia Stock Exchange merger," Res. Int. Bus. Financ., vol. 36, pp. 28-40, Jan. 2016, doi: 10.1016/J.RIBAF.2015.09.002. 